\title{
Study on rationality of different fixed dose drug combinations in tertiary care hospital: an evaluation study
}

\author{
Maddala Rajitha*, Altaf Hussain Shaik, G. B. Simpson, A. Vishwa Shanthi
}

Department of Pharmacology, Nimra Institute of Medical Sciences, Jupudi, Ibrahim Patnam, Andhra Pradesh, India

\author{
Received: 14 October 2019 \\ Revised: 30 December 2019 \\ Accepted: 02 January 2020 \\ *Correspondence: \\ Dr. Maddala Rajitha, \\ Email: maddalarajitha@gmail.com
}

Copyright: (C) the author(s), publisher and licensee Medip Academy. This is an open-access article distributed under the terms of the Creative Commons Attribution Non-Commercial License, which permits unrestricted non-commercial use, distribution, and reproduction in any medium, provided the original work is properly cited.

\begin{abstract}
Background: The fixed dose drug combinations (FDCs) of drugs is defined as product of two or more active ingredients in a defined composition. There is a need to study the pattern of prescription from time to time to evaluate their rationality. In this context we undertook this study to know the prescription pattern of FDC in our setting. To study the rationality of different prescribed FDCs.

Methods: This is a prospective study which is carried out in NIMRA Institute of medical sciences which is a tertiary care teaching private hospital. For this study we have collected one thousand prescriptions of patients for 3 months that is from 10th March 2017 to 25th of June 2017 including both in-patients as well as outpatients. Selection criteria of patients mainly basing on their willingness to give prescriptions. Institutional ethical committee permission was taken for the study. The prescribed FDCs were compared with the essential drug list of FDCs approved by Drugs Controller General of India, July 2018. we have used descriptive statistics to analyze data. The percentage of FDCs used in each class and their contribution to overall FDCs were calculated.

Results: In a total of 2952 drugs were prescribed, of this 747 were FDCs and 2205 were non FDCs. In the prescribed FDCs $89.2 \%$ drugs were rational and $10.8 \%$ drugs were irrational.

Conclusions: From this study, we can conclude that $10.8 \%$ of irrational prescription of fixed dose drug combinations are prescribed in Nimra Institute of Medical Sciences which is a tertiary care teaching private hospital.
\end{abstract}

Keywords: Essential drug list, Fixed-dose combination, Prescription, Rationality

\section{INTRODUCTION}

The goal of drug therapy is to achieve the desired therapeutic response without producing toxicity, i.e., maximizing efficacy yet minimizing untoward effects. Traditional approach with monotherapy is successful in only $50 \%$ of instances, because multiple mechanisms are involved in the pathogenesis of most diseases, and a single drug may not interdict all offending pathways. ${ }^{1}$ The fixed dose drug combination (FDC) of drugs is defined as product of two or more active ingredients in a defined composition. ${ }^{2}$ Although FDCs are available in almost all therapeutic categories, many of them are bizarre combinations. The FDC formulations may have up to 5 or even more ingredients with or without rationality of their presence and in the quality. Essential medicines are those that satisfy the priority health care needs of the population and intended to be available for all the people in the country at all times, in adequate and affordable price for the all the people. The list is prepared with the due consideration to disease prevalence, efficacy, safety, and also comparative cost effectiveness of medicines. All FDCs which are included in the list of essential medicines were included after due deliberation 
in national consultations with scientific justifications. Majority of the FDCs in the both the lists belongs to the antimalarial, antitubercular, antiviral, antiretroviral drugs, which emphasize the importance of FDCs use in the treatment adherence and prevention of drug resistance. Normally after the care full observation of and Central Drugs Standard Control Organization (CDSCO) after due examination of data on rationality, safety, and efficacy, issues approval. On this basis, the state licensing authority (SLA) gives the manufacturing and marketing permission. Incidentally, in the past, SLA issued the license to manufacture and market without asking for no objection from CDSCO. Thus, efficacy and safety and rationality of such FDCs remain questionable.

Due to the difficulties in developing new chemical entities, the pharmaceutical industry finds it easier to develop FDCs. India is primarily the market of generic drugs. As the patent of drug expires, the intense competition among the multiple manufacturers tempts them to give the product a new look claiming multiple advantages without scientific validation of efficacy. The strong marketing pressure, inadequate time and attitude of critical analysis, influences in the prescribing habit toward these FDCs. Senior leaders in medicine from academia and practice who are key opinion leaders influence the prescribing trends of their juniors and have a cascading effect on the medical community. Thus, frequent prescribing and the absence of proper reporting of adverse effects and irresponsibility and negligence of reporting other unwanted adverse effects of drugs becomes the main reason for the lack of knowledge of impact of FDCs.

The high scale turnover and high prescription trend from medical colleges, primary health centers, and general practitioners are often projected as their rationality, safety, and efficacy. The FDC therapy varies among countries. The available combination drugs in the market include both rational and irrational ones. Many articles in print media and Non-governmental organizations questioned the rationality of FDCs. Drug regulator of India (CDSCO) has periodically banned various FDCs due to reasons such as lack of rationale or evidence of safety. ${ }^{3}$ The use of irrational fixed dose combination has a great impact on consumers, society and the nation. There is a need to study the pattern of prescription from time to time to evaluate their rationality. And it is responsibility of every doctor to educate other doctor about the impacts of irrational prescriptions. In this context we undertook this study to know the prescription pattern of FDCs in Nimra Institute of Medical Sciences which is a tertiary care teaching private hospital.

\section{METHODS}

This prospective study carried out in NIMRA Institute of Medical Sciences which is a tertiary care teaching private hospital. For this study we have collected one thousand prescriptions of patients for 3 months that is from 10th
March 2017 to 25th of June 2017 including both inpatients as well as outpatients. Selection criteria of patients mainly basing on their willingness to give prescriptions and also the understandable handwriting of the doctors also considered for the study. Institutional Ethical Committee permission taken for the study.

One thousand prescriptions of patients consulting both inpatients as well as outpatient departments of internal medicine, surgery, obstetrics and gynecology, pediatrics, orthopaedics, otorhinolaryngology, and chest medicine were collected from the hospital pharmacy. The collected data first divided in to two groups one is fixed dose drug combination drugs group and another group is individual drugs group. All the fixed drug combination drugs prescribed in the prescriptions are all noted under the group one, and all the individual drugs prescribed drugs are noted under the group two.

The group 1 drugs which consists of fixed dose drug combinations classified according to anatomic therapeutic and chemical (ATC) classification. The fixed drug combination used will be compared with the list of fixed dose combinations approved by DCGI since 1961 till 12th July 2018. ${ }^{4}$ Descriptive statistics were used to analyze data. the percentage of FDCs in overall prescriptions were noted. In the prescribed FDCs approved or rationally prescribed percentage of FDCs calculated. The percentage of FDCs used in each class and their contribution to overall FDCs calculated.

\section{RESULTS}

The objectives for this study are to study the different fixed dose drug combinations prescribing in tertiary care hospital, to study the percentage of FDCs in overall prescribed drugs, to study the percentage of FDCs in different classes of drugs, to study the rationality of different prescribed FDCs. Out of 1000 prescriptions of patients consulting both in-patients as well as outpatient departments of internal medicine, surgery, obstetrics and gynecology, pediatrics, orthopaedics, otorhinolaryngology, and chest medicine.

A total of 2952 drugs were prescribed, of these 747 prescribed drugs are belongs to FDCs i.e., 25.7\%, 2205 prescribed drugs belongs to others group i.e., $74.7 \%$. Among the prescribed 747 FDCs $89.2 \%$ were rationally prescribed FDCs that is approved by DCGI in July 2018. $10.8 \%$ of prescribed FDCs are irrationally prescribed FDCs that is not present in the essential drug list of DCGI in July 2018. The rationally prescribed FDCs data that is 667 prescribed FDCs classified according to anatomic therapeutic and chemical (ATC) classification. The highest percentage of FDCs were seen in nutritional supplements $(24.8 \%)$, nervous system $(23.1 \%)$. The group wise distribution of drugs, according to ATC classification and FDCs in that category, is given in the (Table 1). 
Table 1: Percentage of different FDCs prescribed in our hospital $(n=747)$ classified according ATC.

\begin{tabular}{|lll|}
\hline $\begin{array}{l}\text { ATC class of } \\
\text { drugs }\end{array}$ & FDC & Percentage (\%) \\
\hline Anti-infective & 136 & 18.2 \\
\hline Blood and CVS & 30 & 4 \\
\hline Gastrointestinal & 44 & 5.8 \\
\hline $\begin{array}{l}\text { Genitourinary } \\
\text { and hormonal }\end{array}$ & 32 & 4.2 \\
\hline Nutritional & 186 & 24.8 \\
\hline Nervous system & 173 & 23.1 \\
\hline $\begin{array}{l}\text { Respiratory } \\
\text { system }\end{array}$ & 132 & 17.6 \\
\hline Others & I4 & 1.87 \\
\hline
\end{tabular}

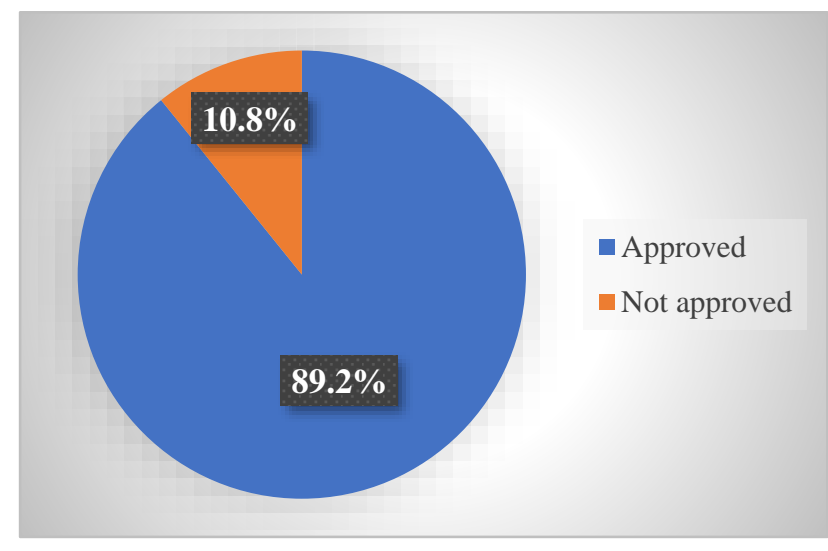

Figure 1: Percent of approved and not approved FDC list by DCGI.



Figure 2: Percentage of commonly prescribing FDCs in nervous system.

Among these FDCs $89.2 \%$ were rational that is approved by DCGI in July 2018 remaining $10.8 \%$ were not approved (Figure 1). Among nervous system prescribed drugs $(23.1 \%)$ most commonly prescribed FDC form is paracetamol with tramadol combination (40\%) (Figure 2). Among anti-infective drugs (18.2\%) most commonly prescribed FDC form (Figure 3) is amoxycillin with clavulanic acid combination (48\%). Among respiratory drugs (17.6\%) most commonly prescribed FDC form (Figure 3) is ambroxyl, guaiphenesin with salbutamol combination $(40 \%)$.

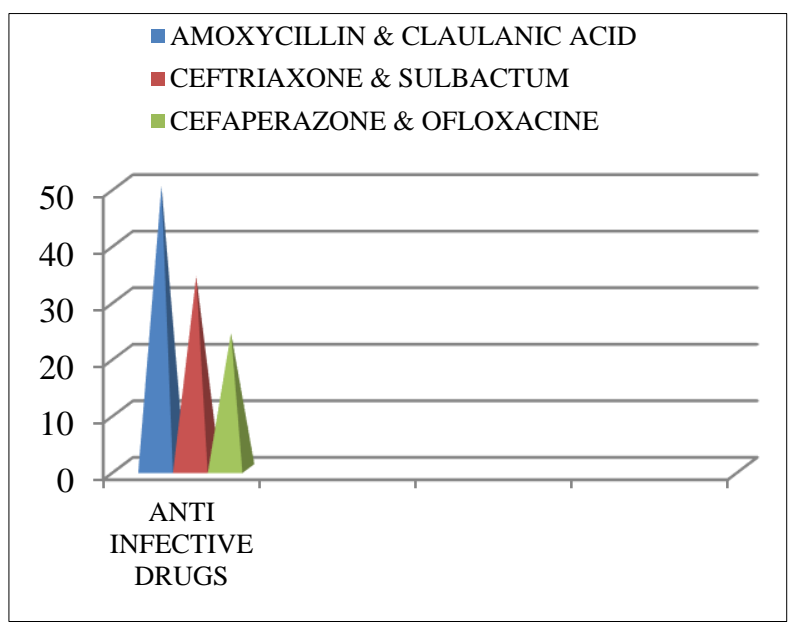

Figure 3: Percentage of commonly prescribing FDCs in anti-infective drugs.

\section{DISCUSSION}

Medicines are an integral part of healthcare. More than one drug is frequently used for the treatment of either single ailment or multiple co morbid conditions. Sometimes two or more drugs combined in affixed ratio into a single dosage form which is termed as FDCs. The FDCs are justified when they demonstrate clear benefits in terms of (a) potentiating the therapeutic efficacy,(b) reducing the incidence of adverse effects, (c) having pharmacokinetic advantage, (d) butter compliance by reducing the pill burden, (e) reducing the dose of individual drugs, (f) decreasing the development of resistance, (g) cheaper than individual drug because of reduced cost from packaging to distribution. the FDCs formulated without due diligence can pose many problems like pharmacodynamic mismatch leading to reduced efficacy and enhanced toxicity, pharmacokinetic mismatch leading to peak efficacy at different times, chemical non compatibility leading to decreased shelf life, drug interactions due to common metabolizing pathways, limitations of dosing titrations. Notwithstanding with the basic principle of formulating FDCs, the Indian medicine market become the world leader of FDCs. As per the rule $122 \mathrm{E}$ of drugs and cosmetics act 1940, the FDCs are considered as new drugs and CDSCO, after due examination of data on rationality, safety, and efficacy, issues approval. CDSCO has periodically banned various FDCs due to reasons of lack of rationale or evidence and potential safety concern. ${ }^{5}$

Rational use of medicines in therapeutics is a much bigger felt need than ever before. Rational use of medicine means use of a right medicine, in the right manner, at right time, in the right type of patients, at a right cost i.e. the rule of right. ${ }^{6}$ Among many reasons of irrational use of medicines, one is the use of unnecessary FDCs. The 
Objectives for this study is to study the different fixed dose drug combinations prescribing in tertiary care hospital, to study the percentage of FDCs in overall prescribed drugs, to study the percentage of FDCs in different classes of drugs, to study the rationality of different prescribed FDC prescriptions in Nimra Institute of Medical Sciences which is a tertiary care teaching hospital. In our study out of 2952 prescribed drugs 747 were FDCs. The total percent of prescribed FDCs are $25.7 \%$. As per drug category analysis, a higher number of FDCs containing nutritional supplements were (24.8) used. While $23.1 \%$ of FDCs were given for nervous system complaints. After the nervous system antiinfective $(18.1 \%)$ respiratory $(17.9 \%)$ prescribed fixed doses prescribed respectively. Our study shows similarity with Balat et al. ${ }^{7}$

As their study concludes that $20.1 \%$ of FDCs contains nutritional supplements and $18.1 \%$ for nervous system complaints. Our study differs from Shaunak et al, as their study concludes $47.74 \%$ of FDCs contains nutritional supplements and $27.02 \%$ FDCs were given for cardiovascular complaints. ${ }^{8}$ According to the study done by Easha et al prescribed of FDCs after the nervous system next highly prescribing FDCs are anti-infective drugs that has the similarity with our study. Among all the FDCs about $10.8 \%$ were irrational according to the list of FDCs approved by Drugs Controller General of India, July 2018. Our study was conducted for short duration and we could not study the adverse effects of the drugs.

\section{CONCLUSION}

There are rational and irrational drugs are available in market so there can be many chances for irrational FDCs prescriptions, this can be minimized by continuous monitoring, and education also proper co-ordination and support from regulatory bodies, academicians, and policy makers.
Funding: No funding sources

Conflict of interest: To know the knowledge of rationale of FDCs

Ethical approval: The study was approved by the Institutional Ethics Committee

\section{REFERENCES}

1. William HF, Brian SB, Lewis R, Vincent LD, Nicolos DV, William JM, et al. A multi factorial trial design to assess combination therapy in hypertension. Arch Intern Med. 1994;154:1461-8.

2. Collier R. Reducing the "pill burden". CMAJ. 2012;184:117-8.

3. CDSCO. Policy Guidelines for the Approval of Fixed Dose Combinations (FDCs) in India.2013. Available at: https://mohfw.gov.in/sites/default/files/ 6404452866Kokate\%20Report.pdf. Accessed 18 June 2016.

4. MEDLINE INDIA; Fixed Dose combinations approved by DCGI(i) since 1961 till July 2018.

5. Gupta YK, Ramachandran SS. Fixed dose drug combinations: Issues and challenges in India. Indian J Pharmacol. 2016;48(4):347-9.

6. Desai SV. Essential drug and rational drug therapy: Phatak A, edi. Bull Soc Rational Ther. 2001;12(1).

7. Balat JD, Gandhi AM, Patel PP, Dikshit RK. A study of use of fixed dose combinations in Ahmedabad, India. Indian J Pharmacol. 2014;46(5):503.

8. Pisal SA, Jadhav SA, Khanvelkar CC, Throat VM, Matule SM. Study of fixed dose combinations in tertiary care hospital. Asian J Pharmaceu Res. 2016;9(3).

Cite this article as: Rajitha $\mathrm{M}$, Shaik $\mathrm{AH}$, Simpson GB, Shanthi AV. Study on rationality of different fixed dose drug combinations in tertiary care hospital: an evaluation study. Int J Basic Clin Pharmacol 2020;9:422-5. 